\title{
Antibody Response of Covishield Vaccine among Health Care Workers at Rajshahi Medical College Hospital- A Cross-Sectional Study
}

\author{
Md. Azizul Haque, ${ }^{1}$ Mohammad Hasan Tarik, ${ }^{2}$ Md. Ruhul Amin, ${ }^{3}$ Md. Jahedul Islam, ${ }^{4}$ Md. Ariful \\ Hasan, ${ }^{5}$ Md. Fazlul Kabir Bhuiyan ${ }^{6}$
}

\begin{abstract}
Background: Nationwide vaccination against SARS CoV-2 is the hope for stopping the pandemic and death from COVID-19. Till today several vaccines have been developed. In Bangladesh, the Covishield vaccine was the first coronavirus vaccine that was administered to health care workers on a priority basis. To assess antibody response in our community, evaluation of response in this group was necessary.
\end{abstract}

Objectives: Our main aim of this study was to evaluate antibody response to SARS CoV-2 after vaccination with the Covishield vaccine in health care workers.

Patients and Methods: It was a cross-sectional type study. Eighty-seven purposively collected health care workers were included in the study. Demographic profile, Co-morbidities, and other variables were recorded in a questionnaire. Blood samples were collected to assess SARS CoV-2 specific antibody.

Results: Mean age in our study was $41.29 \pm 7.87$ years. Most of them were between 35 to 44 years of age. Male: Female ratio was 3.35:1. Obesity (BMI>25) was present in $25.9 \%$ of individuals, hypertension in $33.3 \%$, and DM in $14.9 \%$ of individuals. Overall $82.8 \%$ were vaccinated with the Covishield vaccine, and the remaining were not vaccinated. $96.6 \%$ were found to be antibody positive. All individuals $(100 \%)$ who were either had a history of COVID19 or received at least one shot of the Covishield vaccine were found antibody positive.

Conclusion: Covishield vaccine was found to be highly effective in producing antibody response among healthcare workers.

Keyword: Antibody response, Covishield, SARS CoV-2.

TAJ 2021; 34: No-2: 01-08

\section{Introduction}

Several types of vaccines for COVID-19 had developed within one year since the first cases of COVID-19 due to infection with the SARS CoV-2 infection were reported in December 2019 from Wuhan in the Hubei province of China. ${ }^{1}$ During this time, total COVID-19 cases exceeded 242.3 million and death 4.9 million worldwide. ${ }^{2}$ In

${ }_{1}^{1}$ Associate Professor, Department of Medicine, Rajshahi Medical College, Bangladesh

2 Professor, Department of Medicine, Rajshahi Medical College, Bangladesh

3 Junior Consultant (Medicine), Upazilla Health Complex, Tanore, Rajshahi

${ }^{4}$ Registrar, Department of Medicine, Rajshahi Medical College Hospital, Bangladesh

${ }^{5}$ Registrar, Department of Medicine, Rajshahi Medical College Hospital, Bangladesh

${ }^{6}$ OSD, DGHS, Attached: Department of Neuromedicine, Rajshahi Medical College Hospital, Bangladesh 
Bangladesh total number of confirmed cases were more than 1.5 million, and total death from COVID-19 were more than 27 thousand. $^{3}$ Nationwide vaccination against the Severe Acute Respiratory Syndrome Coronavirus 2 (SARS CoV-2) infection, the cause of Coronavirus disease-2019 (COVID-19) pandemic, is currently ongoing across the globe. ${ }^{4}$ In Bangladesh 1 st vaccination against SARS CoV 2 was first started on 27 January 2021. Since then, 1 st dose of vaccine was given to 38.8 million people, and 2 nd dose of vaccine was given to 1.9 million people, which is $23 \%$ and $12 \%$ of the total population, respectively. ${ }^{3}$

Several studies have evaluated the immune response to the Covishield vaccine. The response rate range from $69.9 \%$ to $98.1 \% .^{1,4,5,6,7}$ Frequency of post-vaccination mild to moderate side effects were range from $18.1 \%$ to $82 \%$. ${ }^{4,6}$ In a study performed in India; comorbidities were found to be significantly related to an increase in the nonseropositivity rate by $>4$ fold. Also, male gender was found to be a significantly increase in the nonseropositivity rate by $>3$ fold. ${ }^{4}$ The proportion of detectable antibodies were found to be similar across age group. ${ }^{4,7}$ Our study was

\section{Results}

Table 1: Demographic characteristics $(\mathrm{N}=87)$

\begin{tabular}{|c|c|c|c|}
\hline \multirow{8}{*}{ 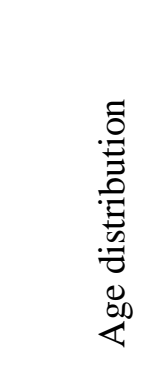 } & & Frequency & $\%$ \\
\hline & 1. $<25$ years & 1 & 1.1 \\
\hline & 2. $25-29$ years & 5 & 5.7 \\
\hline & 3. $30-34$ years & 8 & 9.2 \\
\hline & 4. $35-39$ years & 24 & 27.6 \\
\hline & 5. $40-44$ years & 21 & 24.1 \\
\hline & 6. 45-49 years & 13 & 14.9 \\
\hline & 7. $>50$ years & 15 & 17.2 \\
\hline \multirow[b]{2}{*}{ Gender } & 1. Male & 67 & 77.0 \\
\hline & 2. Female & 20 & 23.0 \\
\hline \multirow{2}{*}{ Religion } & 1. Islam & 79 & 90.8 \\
\hline & 2. Hindu & 8 & 9.2 \\
\hline
\end{tabular}

Mean age: $41.29 \pm 7.85$ years

In our study mean $\pm \mathrm{SD}$ age of the respondents was $41.29 \pm 7.85$ years. Most of our patients were between 35-44 years age group (51.7\%) (Table-1). M: F ratio was 3.35:1. Obesity was found in 46 $(52.9 \%)$ individuals, and only $11(12.6 \%)$ had a normal BMI. Obesity was found to be more frequent 
among females (75\%) compared to males (46.3\%) (Table 2). Only $2(2.3 \%)$ had a history of smoking, and only $1(1.1 \%)$ respondent had a history of betel nut use (Table 3 ).

Table 2: Category of BMI (N=87)

\begin{tabular}{lccc} 
BMI & \multicolumn{2}{c}{ Gender } & Total \\
& 1. Male & 2. Female & $\mathrm{n}(\%)$ \\
1. Normal & $\mathrm{n}(\%)$ & $\mathrm{n}(\%)$ & $11(12.6)$ \\
2. Overweight & $10(14.9)$ & $1(5.0)$ & $30(34.5)$ \\
3. Obese & $26(38.8)$ & $4(20.0)$ & $46(52.9)$ \\
Total & $31(46.3)$ & $15(75.0)$ & 87
\end{tabular}

Mean BMI: 25.59 \pm 2.81

Table 3: Personal history

Frequency \%

Smoking 1. Smoker

2

2.3

history

2. Ex-smoker

4

4.6

3. Nonsmoker

81

93.1

Betel nut use

1

1.1

Table 4: Comorbidities ( $\mathrm{N}=87)$

IHD

Frequency

$\%$

Hypertension

29

1.1

Diabetes

13

33.3

Bronchial asthma

8

14.9

Obesity

4

9.2

Major operation

5

4.6

5.7 
Table 5: Drug history $(\mathrm{N}=87)$

$\begin{array}{lcc} & \text { Frequency } & \% \\ \text { Regular sedative } & 1 & 1.1 \\ \text { Antihypertensive } & 28 & 32.2 \\ \text { Antidiabetic } & 13 & 14.9 \\ \text { Anti-Platelet } & 2 & 2.3 \\ \text { Lipid-lowering } & 10 & 11.5 \\ \text { Regular anti-ulcerant } & 5 & 5.7 \\ \text { Prophylaxis for COVID-19 } & 4 & 4.6 \\ \text { Steroid and } & 2 & 2.3 \\ \text { immunosuppressive } & & \end{array}$

Hypertension was present in $33.3 \%$ of individuals, diabetes in $14.9 \%$, and bronchial asthma in $9.2 \%$ of individuals. We did not have any respondents having CKD or cancer (Table 4). $32.2 \%$ of the subjects were taking antihypertensive, $14.9 \%$ were taking antidiabetic, and $11.5 \%$ were taking lipid-lowering regularly. 2 respondents were on steroid/immunosuppressive medications, and 4 (4.6\%) had taken prophylaxis for COVID-19 (Table 5).

Table 6: History and exposure to COVID-19

$\begin{array}{llccc} & & \text { Frequency } & \% & \text { Mean } \pm \text { SD } \\ \text { History of COVID } & & 12 & 13.8 & \\ \text { Duration since COVID infection } & 1 .<6 \text { months } & 3 & 25.0 & 225.25 \pm \\ & 2 .>6 \text { months } & 9 & 75.0 & 84.47 \text { days } \\ \text { Family member affected by COVID } & & 12 & 13.8 & \\ \text { Exposure to COVID-19 } & & 68 & 78.2 \\ \text { Place of exposure } & \text { 1. Hospital } & 39 & 57.4 \\ & \text { 2. Private chamber } & 4 & 5.9 \\ & \text { 3. Both } & 25 & 36.8 \\ \begin{array}{l}\text { Performed aerosol-generating } \\ \text { procedure }\end{array} & & 15 & 17.2 \\ \begin{array}{l}\text { Frequency of aerosol-generating } \\ \text { procedure }\end{array} & \text { 1. Frequently } & 3 & 20.0 \\ & \text { 2. Occasionally } & 9 & 60.0\end{array}$

Among the respondents, $12(13.8 \%)$ had a history of COVID-19. Mean \pm SD duration since the time of COVID-19 was $225.25 \pm 84.47$ days. $25 \%$ of those had a history of COVID-19 within six months. $13.8 \%$ had a history of at least one family member affected with COVID 19. The majority of the respondents 
(78.2\%) had a history of exposure to COVID 19 patients. 57.4\% (39) had been exposed to COVID 19 patients at a government hospital, $5.9 \%$ at the private chamber, and $36.8 \%$ at both practicing areas. $82.8 \%$ had never performed aerosol-generating procedures (Table 6).

Table 7: Previous vaccination status

$\begin{array}{lcc} & \text { Frequency } & \% \\ \text { Vaccinated as per EPI schedule } & 73 & 83.9 \\ \text { HBV } & 74 & 85.1 \\ \text { Influenza } & 13 & 14.9 \\ \text { Meningococcus } & 6 & 6.7 \\ \text { Pneumococcus } & 2 & 2.3\end{array}$

Table 8: Vaccination status against COVID-19 (N=87)

$\begin{array}{lccc} & \text { "0" Shot } & \text { "1" shot } & \text { "2" shots } \\ & \mathrm{n} & \mathrm{n} & \mathrm{n} \\ & (\%) & (\%) & (\%) \\ \text { Vaccination status- all } & 11 & 4 & 72 \\ & (12.6) & (4.4) & 62.8) \\ \text { Vaccination status of those } & 9 & 4 & (82.7) \\ \text { who were never infected with } & (12.0) & (5.3) & \end{array}$

Table 9: Covishield vaccination duration and side effects $(\mathrm{N}=76)$
Duration since Covishield 1
Frequency
1. $<60$ days
2
74
$\%$
Mean \pm SD
2. $>60$ days
23
97.3
$99.83 \pm 9.89$ days
Side effects after Covishield 1
Duration since Covishield 2

$$
\begin{aligned}
& \text { 1. }<21 \text { days } \\
& \text { 2. }>21 \text { days }
\end{aligned}
$$

1
71
30.7
1.4
98.6
$40.39 \pm 7.32$ days
Side effects after Covishield 2
10
13.9
In our study, along with EPI vaccines, most of the respondents (85\%) were vaccinated against HBV, but the frequency of other vaccinations was very low (Table 7). In our study, 82.8\% (72) had completed two doses of the Covishield vaccine. 4.4\% (4) had received a single dose, and $12.6 \%$ (11) did not receive any dose of the Covishield vaccine (Table 8$)$. Mean $( \pm$ SD) duration from 1 st dose of vaccine was 99.83 $( \pm 9.89)$ days, and $97.3 \%$ had received 1 st dose $>60$ days back. Mean $( \pm$ SD) duration from 2 nd dose of vaccine $40.39( \pm 7.32)$ days and $98.6 \%$ had received the second dose more than 21 days back. Mild to moderate side effects were observed in $30.7 \%$ after 1 st dose and $13.9 \%$ after two and dose (Table 9). 
Table 10: Antibody response among different groups depending on exposure to COVID-19 and/or vaccination (N=87)

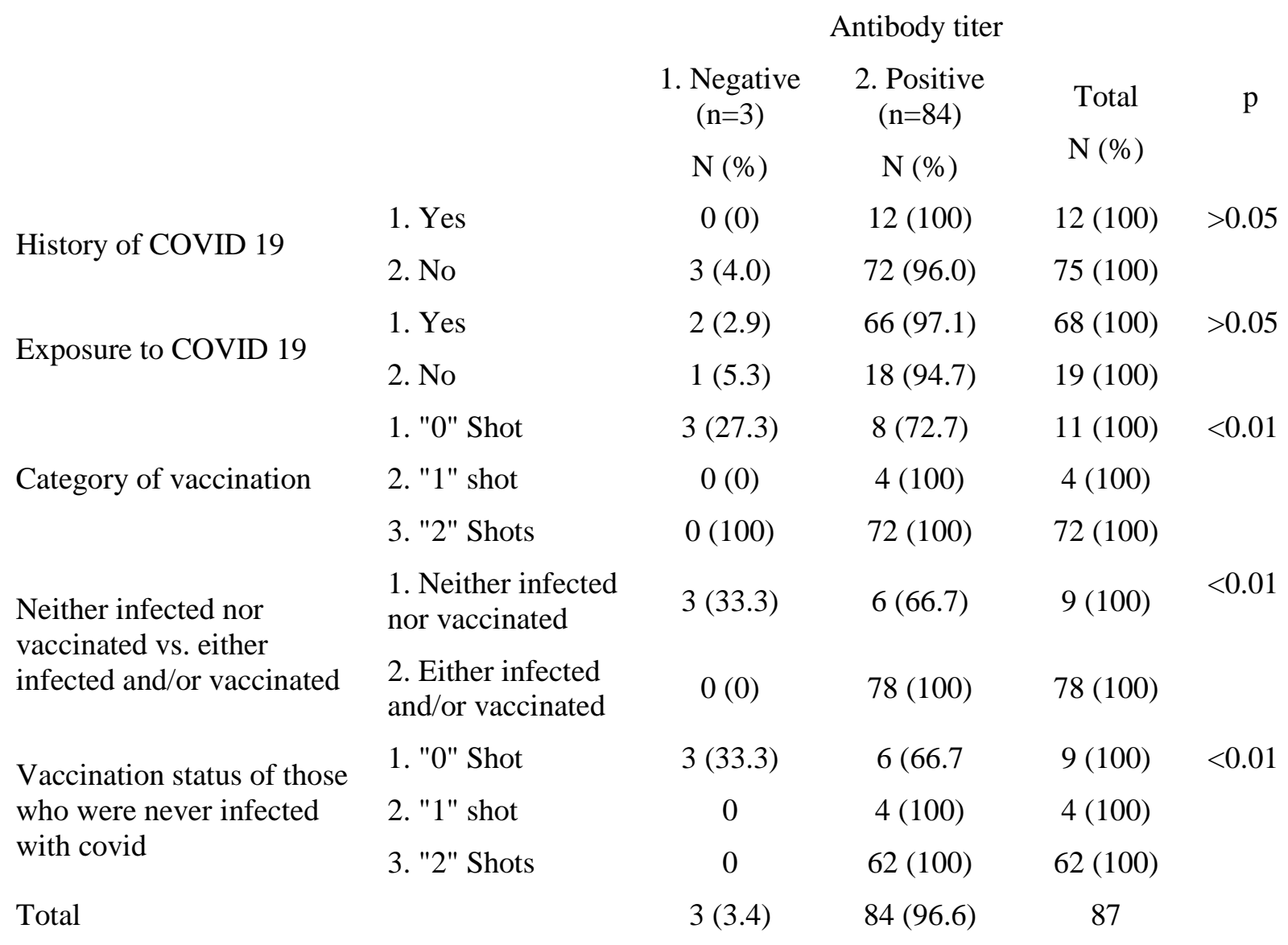

Mean antibody titer: $11.64( \pm 7.79)$

Overall antibody against SARS COV-2 was positive among $96.6 \%$ (84) respondents and negative in only $3.4 \%$ (3). Three antibody-negative individuals were neither vaccinated nor had a history of COVID-19 infection. Antibody titer was found positive in all individuals (78) who were either had a history of COVID-19 or received at least one shot of Covishield vaccine. Antibody response is significantly higher among those responders who were either infected with COVID-19 or vaccinated with Covishield vaccine compared to those who were neither infected with COVID-19 nor vaccinated $(\mathrm{p}<0.01)$ (Table 10).

\section{Discussion}

In our study, mean age was similar to most other studies, but a lower mean was observed by Borkakoty et al. ${ }^{5}$ and Chau et al. $^{7}$ and a higher mean was observed by Njarekkattuvalappil et al. ${ }^{8}$. Sing et al. ${ }^{4}$ and Njarekkattuvalappil et al. ${ }^{8}$ showed a male preponderance which is similar to our study, although the proportion of males was much higher in our study. Female preponderance was seen in some studies. ${ }^{1,5,6,7}$ Sing et al. $^{4}$ and Njarekkattuvalappil et al. ${ }^{6}$ had found higher BMI, which are $67.5 \%$ and $61.1 \%$, respectively. But a lower frequency of overweight and obesity was observed by Sing et al. ${ }^{4}$. High frequency of overweight (BMI>23) and Obese (BMI>25) individuals were observed among health care workers (HCW) included in our study. Affluence, sedentary, and lack of exercise may be the cause.

Although the total frequency of comorbidities was high in our study, the frequency of IHD was less $(1.1 \%)$ compared to Sing et al. $(2.5 \%)^{4}$. The frequency of comorbidities in our study was very 
TAJ December 2021; Volume 34 Number-2

high, which is far more than most other studies. Sing et al. ${ }^{4}$ had shown that $24.3 \%$ of the respondents had at least one comorbidities (HTN, DM, IHD, dyslipidemia), and hypertension was observed in $18.3 \%$. Whereas in our study, it was $33.3 \%$. Jeewandara et al. ${ }^{1}$ and Njarekkattuvalappil et $\mathrm{al}^{6}$ had found the frequency of co-morbid conditions to be $7.9 \%$ and $19.4 \%$, respectively.

The proportion of respondents having a history of COVID-19 was higher than that observed by Jeewandara et al. ${ }^{1}$ and Njarekkattuvalappil et al. ${ }^{8}$ (3.9\% and 5.6\%, respectively). A higher frequency of COVID-19 was also observed by Sing et al. ${ }^{4}$ Different studies had observed different frequencies of side effects after receiving Covishield vaccine ranging from $18.1 \%$ to $82 \%$., Including ours, none of the studies had observed any severe side effects after receiving the vaccine dose.

The seroconversion rate in the current study was $100 \%$. A high rate of seroconversion after the Covishield vaccine was observed by all previous studies ${ }^{1,4,5,6,7}$, the lowest being observed by Njarekkattuvalappil et al. ${ }^{6}$, which is $69.9 \%$. The Single-dose Covishield vaccine was found to induce a high level of antibody to the receptorbinding domain (RBD) and ACE2. Blocking antibody was present in naïve individuals, which is greater than the immune response in those who experienced a mild or asymptomatic natural infection. ${ }^{1}$ Seroconversion was $>95 \%$ after two and doses of the Covishield vaccine in most of the studies. ${ }^{4}$ Evidence for optimal vaccine dose, time, and need for booster dose remains scarce ${ }^{6}$, as well as the effectiveness of the vaccine towards different concerning variants of SARS CoV-2, is also to be defined.

\section{Conclusion}

The antibody response of the Covishield vaccine was found to be high in our setting, even after a single dose. Mutation of virus and newer variants of SARS CoV-2 pose a challenge to the effectiveness of the vaccine. The limitations of our study were the small sample size and purposive sampling process.

\section{References}

1. Jeewandara C, Kamaladasa A, Pushpakumara PD, Jayathilaka D, Aberathna IS, et al. Immune responses to a single dose of the AZD1222/Covishield vaccine in health care workers. Nature communications 2021;12(4617): 1-9.

2. Available at: https://covid19.who.int. Cited on 21 Oct, 2021.

3. Available at: http://103.247.238.92/webportal/pages/covid19.php. Cited on 21 Oct, 2021.

4. Sing AK, Phatak SR, Sing R, Bhattacharjee K. Singh NK. Gupta A, Sharma A. Antibody response after second dose of ChAdOx1-nCOV (Covishield TM) and BVB-125 (Covaxin TM) among health care workers in India: Final results of cross- sectional coronavirus vaccine-induced antibody titre (COVAT) study. Vaccine 2021; 39 (44): 6492-6509.

5. BorkakotyB, Sarmah MD, BhattacharjeenCK, Bali N, Gogoi G. Antibody response after a single dose of ChAdOx1-nCOV (Covishield ${ }^{\mathrm{TM}} 囚$ ) vaccine in subjects with prior SARS-CoV2 infection: Is a single dose sufficient? Available at: medRxiv 2021.06.15.21258346;DOI:https://doi.org/10.1101/ 2021.06.15.21258346. Cited on 31 Oct,2021.

6. Njarekkattuvalappil SK, Bhaskaran R, Raj S, Jose P, Rafi AM, Thomas J, Innah SJ, Raphael L, Unnikrishnan UG, Rajmohan P, Valsan C, Kuttichira $P$. Prospective serosurveillance among healthcare workers vaccinated with ChAdOx1 nCoV-19 Corona vaccine in a tertiary hospital of Kerala, India. Available at: https://www.medrxiv.org/content/10.1101/2021.06.29 .21259686v1. Cited on 31 Oct,2021.

7. Chau NVV, Nguyet LA, Truong NT, Toan LM, Dung NT, Hung LM, Nhan MT, Man DNH, Ngoc NM, Thao HP, Tu TNH, Mai HK, Hung DT, Ny NTH, Thanh LK, Anh NT, Hong NTT, Nhu LNT, Yen LM, Choisy M, Thanh TT, Thwaites G. Immunogenicity of OxfordAstraZeneca COVID-19 vaccine in Vietnamese healthcare workers. Available at: https://www.medrxiv.org/content/10.1101/2021.07. 08.21260162v1. Cited on 31 Oct, 2021. 
8. Chanakya GV, Srikantam A. Comparative quantitative analysis of SARS- CoV-2 Spike neutralizing antibody titers following two anti COVID-19 vaccines in India Available at: https://www.medrxiv.org/content/

10.1101/2021.08.28.21262753v2. Cited on 31 Oct, 2021

All correspondence to Dr. Md. Azizul Haque Associate Professor, Department of Medicine Rajshahi Medical College Email:drazadbd@gmail.com 